\title{
Research on water environment and water saving management of swimming places
}

\author{
Huang $\mathrm{Yi}^{1, \mathrm{a}}$ \\ ${ }^{1}$ Xianyang Vocational Technical College, Xianyang, Shaanxi, China, 712000
}

\begin{abstract}
The swimming gymnasium is a social public water industry with water as the carrier, which integrates fitness, education and entertainment.It is an important part of water saving work to strengthen the water environment and water saving management of swimming places because of its large water consumption, complex water users and relatively concentrated water consumption time.In recent years, with the rapid development of the national economy and the continuous improvement of people's living standards, the demand and construction of swimming venues have rapid development, consuming a lot of water resources.
\end{abstract}

\section{The main water use in the swimming place}

The main water use links of swimming venues focus on shower water, overflow loss of pool surface and filter backwash water, etc.

\subsection{Shower and compulsory shower water}

Showers with forced showers are essential for water consumption. The amount of manual control outflow is about $90 \mathrm{~L} /$ (man - field); if automatic induction control is used, the water consumption is about $60 \mathrm{~L} /(\mathrm{man} \cdot$ field).

Forced shower is also an essential water consumption. At present, most of the natatorium adopts automatic induction control to save water consumption.

\section{2 make up water}

At present, most of the swimming pools are filled with water and constant water level intermittent water replenishment mode.Filling is when the pool is filled up (very briefly, with a thin film overflow to remove surface matter) before opening, and filled up again in the afternoon or evening.Although this method is more water-saving than overflow type, it still has a lot of waste.

Non-full constant water level replenishment is to limit the water level to $10-15 \mathrm{~cm}$ offshore according to the above water level fluctuation.If there is no other drainage, there is no need to replenish water.However, when the pool is not full, dirt such as oil on the water surface will stick to the pool wall due to the fluctuation of the water surface, forming a circle of gray and black stains around the water surface, which will affect

$\overline{{ }^{a} \text { Hyvv606@outlook.com }}$ people's visual experience.The following measures are often taken to eliminate this:

(1) There is no backwash water after closing the field. After standing in the evening, the dirt on the pool wall is removed manually with a cotton rag with strong oil absorption before the morning cycle in time.

(2) When the filter needs backflushing after closing the field, it should be cleared by the above manual method before backflushing and water replenishment;

(3) Depending on the situation of water surface dirt, the film overflows periodically when the water is full for a short time to remove visual pollutants on the water surface.This method should be carried out before filtering and backwashing, so that about $10 \mathrm{~cm}$ of water under the pool surface can be used for backwashing (at this time, it is better for both filters to backwash), so as to finally keep the water level in the pool at a constant state, and avoid waste caused by fluctuation and overflow after the opening.

\subsection{Water consumption for backwashing of pressure filter}

In constant water level water replenishment, the filter backwash drainage and primary water drainage are the direct causes of water replenishment.According to the design value of the specification, the amount of water required by the backwashing of the heavy filter material and the light filter material is roughly equal. For the filter with a diameter of $2.5 \mathrm{~m}$, it is calculated to be about $30 \mathrm{~m} 3 /$ time.However, in the actual operation process, the water consumption of initial filtration and drainage is more than $70 \mathrm{~m} 3 /$ time - Taiwan. The reasons are as follows:

(1) Backwash intensity is not enough, resulting in drainage water quality in a long time is still difficult to meet the requirements; 
(2) lest the filter material is not clean, excessive extension of the backwash (or number of times) and the initial filter water drainage time;

(3) modeling, regardless of the filter material pollution degree, each backwashing time or times are basically the same;

(4) lack of experience in operation, improper methods, in the whole process of washing to maintain the same flow. The backwash of the filter can not be carried out by personal judgment, and the specific value should be determined according to the pressure gauge difference between the inlet and outlet of the filter and the observation of the sampling water quality.

In the off-season of winter and spring, the filter rarely needs to backwash due to saturation when the pressure difference reaches the specified value. Most of the filter needs to backwash once in half a month for protection, and the washing duration is short and the displacement is less.And in the summer and autumn peak seasons, the filter backwash cycle is greatly shortened, generally average 4 days of backwash wash once, and the wash water is relatively large off-season.Therefore, in summer and autumn, the operation of filter backwash is very important for its water saving.

\subsection{Bottom cleaning discharge}

Due to the reasons of outage, dication, low circulation velocity, the bottom of the swimming pool will deposit a thin layer of stains, even if the water quality is very good, it will therefore give a person a sense of visual pollution, so it should be removed regularly.Generally speaking, summer and autumn season should be cleaned once a week, winter and spring off-season half moon or January cleaning once can be.According to the water consumption of about 5OM3 for each cleaning, the annual water consumption of a pond will reach about $1500 \mathrm{~m} 3$. Such as direct discharge will cause greater waste.

\section{Involved standards and main contents}

The standards involved mainly include GB/T 38802-2020 "Code for Water Saving Management in Swimming Places".

\subsection{Range}

This standard stipulates related terms and definitions, design requirements, technical requirements and management requirements for water conservation in swimming places.

This standard applies to all kinds of swimming places such as artificial swimming places and water recreational facilities.

\subsection{Terms and definitions}

For the convenience of understanding, three main terms and definitions are given in this standard, such as swimming place and water replenishment rate.The specific interpretation is as follows:

1) Swimming places

Indoor and outdoor water surface (area) and its facilities and equipment can meet people's swimming, fitness, training, competition, entertainment and other activities.

2) Hydration rate

The proportion of the total amount of water replenished to the pool per unit of time.

3) Circulating water supply system

The used swimming pool water is pumped out from the pool according to the stipulated flow rate and flow rate, filtered and purified to make the pool water clear and sterilized, and then returned to the system for reuse in the swimming pool after meeting the relevant water quality standards.

\subsection{Basic requirements}

The paper puts forward the management requirements of promoting water conservation in the natatorium from the aspects of water conservation management system, water quality, sanitary conditions, measurement, water use plan, daily management, water balance test, training and publicity.

(1) We should establish and improve the management system of water conservation, implement the post responsibility system of water conservation management, and provide management personnel.

(2) The swimming place hygiene shall meet the requirements of the Swimming Place Hygienic Code.

(3) The water quality of the initial water filling, water changing and water replenishing in the operation of the swimming pool shall meet the requirements of GB 5749, and the water quality of the pool shall meet the requirements of CJ/T 244.

(4) Water measuring instruments shall be equipped in accordance with the requirements of GB 24789 and ensure their normal operation. There should be complete water supply and drainage pipe network diagrams and water measuring instruments equipped with network diagrams.

(5) The annual water use plan shall be strictly implemented, and the original records and statistical ledgers of water use shall be complete and standardized.

(6) The inspection and maintenance of water facilities should be strengthened to prevent leakage and leakage. Water balance test should be carried out at least once every 5 years according to the requirements of $\mathrm{GB} / \mathrm{T}$ 12452.

(7) Water saving signs should be posted in a prominent position.

(8) Water conservation training shall be carried out on a regular basis to staff. 


\subsection{Equipment requirements}

Mainly for natatorium swimming pool, shower, toilet water appliances and other norms.For swimming pool water purification should adopt the water circulation mode according to local conditions, encourage the use of advanced water-saving technology circulation purification system;On the basis of ensuring the humidity of the swimming gymnasium, the evaporated water is recovered by the dehumidification equipment.Encourage qualified swimming venues to use pool insulation film. The swimming pool should be cleared of sediment regularly, and water-saving sewage absorption equipment should be adopted. It is appropriate to recycle the discharged sewage. The backwash water of the filtration equipment and the overflow water of the swimming pool should be recycled and multistage utilized.When cleaning the pool bank, high pressure water gun and other water-saving equipment should be used.The swimming pool shall be equipped with separate metering devices and water quality monitoring and control systems.
The shower requirements are mainly in line with the requirements of water-saving evaluation value in GB 28378 "Restricted Value of Water Efficiency for Shower and Its Water Efficiency Grade".

For toilets and other swimming places, water appliances shall meet the requirements of GB 25502, GB 30717, GB 28377 and GB 25501 for water-saving evaluation value.

\subsection{Norm requirements}

(1) Investigate quota standards in relevant specifications The quota standards in the relevant codes for swimming pools were investigated. The daily supplementary water quantity of swimming pools in the Technical Specification for Water Supply and Drainage Engineering of Swimming Pool (CJJ122-2017) was shown in Table 1, and the supplementary water quantity of swimming pools and the upstream music pit in the Design Code for Building Water Supply and Drainage (GB 50015 -- 2003) was shown in Table 2.

Table 1 Daily replenishment of the swimming pool

\begin{tabular}{|c|c|c|c|c|}
\hline Number & $\begin{array}{l}\text { Purpose and type of } \\
\text { swimming pool }\end{array}$ & $\begin{array}{l}\text { Swimming Pool } \\
\text { Environment }\end{array}$ & $\begin{array}{l}\text { Water Replenishment } \\
\text { (\%) (as a percentage of } \\
\text { pool volume) }\end{array}$ & note \\
\hline \multirow{2}{*}{1} & \multirow{2}{*}{$\begin{array}{l}\text { Competitions and } \\
\text { special categories }\end{array}$} & indoor & $3-5$ & \multirow{2}{*}{$\begin{array}{l}\text { Contains multi - purpose, multi - } \\
\text { function and artistic performance } \\
\text { pool }\end{array}$} \\
\hline & & outdoor & $5-10$ & \\
\hline \multirow{2}{*}{2} & \multirow{2}{*}{$\begin{array}{l}\text { Public and water } \\
\text { recreation }\end{array}$} & indoor & $5-10$ & \\
\hline & & outdoor & $10-15$ & \\
\hline \multirow{2}{*}{3} & \multirow{2}{*}{$\begin{array}{c}\text { Children、Young } \\
\text { children }\end{array}$} & indoor & $\geq 15$ & \\
\hline & & outdoor & $\geq 20$ & \\
\hline \multirow{2}{*}{4} & \multirow{2}{*}{ Private } & indoor & 3 & \\
\hline & & outdoor & 5 & \\
\hline
\end{tabular}

Table 2 Replenishment of swimming pools and amusement pools

\begin{tabular}{|c|c|c|c|}
\hline Number & \multicolumn{2}{|c|}{ Types and characteristics of swimming pools } & $\begin{array}{l}\text { Percentage of daily } \\
\text { replenishment of pool volume }\end{array}$ \\
\hline \multirow{2}{*}{1} & \multirow{2}{*}{ Competition pool, training pool, diving pool } & indoor & $3-5$ \\
\hline & & outdoor & $5-10$ \\
\hline \multirow{2}{*}{2} & \multirow{2}{*}{ Public swimming pool、 amusement pools } & indoor & $5-10$ \\
\hline & & outdoor & $10-15$ \\
\hline \multirow{2}{*}{3} & \multirow{2}{*}{ Children's pool、Young children's pool } & indoor & $\geq 15$ \\
\hline & & outdoor & $\geq 20$ \\
\hline \multirow{2}{*}{4} & \multirow{2}{*}{ Family swimming pool } & indoor & 3 \\
\hline & & outdoor & 5 \\
\hline
\end{tabular}


(2) Investigate the water quota of swimming venues in all provincial administrative regions.For provincial administrative region involved in swimming pool water quota of sorting, some provinces (such as Beijing, tianjin, liaoning, heilongjiang, shandong, yunnan, etc.) for the swimming pool to fill water the indoor and outdoor, some provinces (such as Beijing, shanxi, Inner Mongolia, liaoning, etc.) to join the shower water quota and the audience, as shown in table 3 .

Table 3 Water quota of swimming venues in each provincial administrative region

\begin{tabular}{|c|c|c|c|c|c|c|c|c|c|}
\hline \multirow{3}{*}{ Number } & \multirow{3}{*}{ provinces } & \multirow{3}{*}{ year } & \multicolumn{4}{|c|}{ Filling water } & \multicolumn{2}{|l|}{ shower } & \multirow[b]{2}{*}{ audience } \\
\hline & & & indoor & outdoor & $\begin{array}{l}\text { Indistingu } \\
\text { ishable }\end{array}$ & note & shower & note & \\
\hline & & & \multicolumn{3}{|c|}{$\%$ (Pool volume ratio $)$} & & $\begin{array}{l}\mathrm{L} / \text { perso } \\
\text { n-time }\end{array}$ & & $\begin{array}{l}\text { L/person- } \\
\text { session }\end{array}$ \\
\hline 1 & Beijing & 2001 & 5 & 10 & & & 60 & $\begin{array}{l}\text { Athlete } \\
\text { shower }\end{array}$ & 3 \\
\hline 2 & Tianjin & 2003 & $9-11$ & $6-8$ & & & & & \\
\hline 3 & Hebei & 2014 & & & 10 & $\begin{array}{l}\text { Adjustment } \\
\text { coefficient : } \\
0.8-1.2\end{array}$ & 50 & $\begin{array}{l}\text { Athlete } \\
\text { shower } \\
\text { Adjustment } \\
\text { coefficien : } \\
1.0-1.6\end{array}$ & \\
\hline 4 & shaanxi & 2015 & & & & & $25-40$ & $\begin{array}{l}\text { Athlete } \\
\text { shower }\end{array}$ & 3 \\
\hline 5 & $\begin{array}{l}\text { Inner } \\
\text { Mongolia }\end{array}$ & 2015 & & & 0.12 & unit: $\mathrm{m}^{3} / \mathrm{m}^{2} \cdot \mathrm{d}$ & 30 & $\begin{array}{l}\text { Athlete } \\
\text { shower }\end{array}$ & 3 \\
\hline \multirow{2}{*}{6} & \multirow{2}{*}{ Liaoning } & \multirow{2}{*}{2008} & $3-5$ & $5-10$ & & $\begin{array}{l}\text { Competition, } \\
\text { training }\end{array}$ & \multirow{2}{*}{$30-40$} & \multirow{2}{*}{$\begin{array}{l}\text { Athlete } \\
\text { shower }\end{array}$} & \multirow{2}{*}{$3-5$} \\
\hline & & & $5-10$ & $10-15$ & & $\begin{array}{l}\text { public } \\
\text { Amusement }\end{array}$ & & & \\
\hline 7 & Ji Lin & 2010 & & & 0.2 & unit: $\mathrm{m}^{3} / \mathrm{m}^{2} \cdot \mathrm{d}$ & & & \\
\hline 8 & $\begin{array}{l}\text { Heilongjia } \\
\text { ng }\end{array}$ & 2016 & $5-10$ & $10-15$ & & & & & \\
\hline 9 & Jiangsu & 2012 & & & 10 & & 70 & shower & \\
\hline 10 & zhejiang & 2015 & & & 10 & & & & \\
\hline 11 & Anhui & 2014 & & & $15-20$ & & & & \\
\hline 12 & Fujian & 2013 & & & 15 & & & & \\
\hline 13 & Shandong & 2010 & 5 & 10 & & & & & \\
\hline 14 & Henan & 2009 & & & 10 & $\begin{array}{l}\text { Adjustment } \\
\text { coefficien : } \\
0.8-1.2\end{array}$ & 50 & $\begin{array}{l}\text { Athlete } \\
\text { shower }\end{array}$ & \\
\hline 15 & Hunan & 2014 & & & 20 & & & & \\
\hline 16 & Hainan & 2008 & & & 15 & & & & 3 \\
\hline 17 & $\begin{array}{l}\text { Chongqin } \\
\mathrm{g}\end{array}$ & 2007 & & & 12 & & & & \\
\hline 18 & Sichuan & 2010 & & & 15 & & & & \\
\hline 19 & Guizhou & 2011 & & & 200 & unit: $\mathrm{L} / \mathrm{m}^{2} \cdot \mathrm{d}$ & & & \\
\hline 20 & Yunnan & 2013 & 10 & 15 & & & & & \\
\hline 21 & Shanxi & 2013 & 8 & 10 & & & & & \\
\hline 22 & Gansu & 2017 & 8 & 10 & & & & & \\
\hline \multirow{2}{*}{23} & \multirow{2}{*}{ Ningxia } & \multirow{2}{*}{2008} & & & \multirow{2}{*}{8} & & $30-40$ & $\begin{array}{l}\text { Athlete } \\
\text { shower }\end{array}$ & \\
\hline & & & & & & & 30 & public & \\
\hline
\end{tabular}


For indoor and outdoor swimming places, as well as shower and audience,the quota index of water intake is given. See Table 4 for details.

Table 4 water intake quota for swimming

\begin{tabular}{|c|c|c|c|}
\hline Use and Type & Quota unit & Advanced value & Constraint value \\
\hline indoor & $\%$ (Pool volume ratio $)$ & 4 & 7 \\
\hline outdoor & $\%$ (Pool volume ratio $)$ & 7 & 10 \\
\hline shower & L/person-time & 25 & 40 \\
\hline audience & L/person-time & 2.5 & 3 \\
\hline
\end{tabular}

\section{Conclusion}

Due to the large aount of water consumption and relatively concentrated water consumption time in swimming venues, it is an important means to promote water saving work to strengthen water use and water saving management in swimming venues and comply with the relevant requirements of Management specification for water-saving of swimming places.

\section{References}

1. GB/T 38802-2020, Management specification for water-saving of swimming places $[\mathrm{S}]$.
2. Yan Kejun,Li Weiping,Sun Yanbai,et al.Water saving, energy saving and economic analysis of swimming pool in operation.[M].Low Temperature Architecture Technology.2003,(03):75-76.

3. Li Jinjian,Song Zhiliang.Feasibility study on the management and development of university natatorium.[M].Industrial Technology Innovation. 2020, 2(22):73-74.

4. Luo Hongwei.Energy saving technology of Swimming Teaching Hall in Jiangxi Modern Vocational and Technical College.[D].Nanchang University.2013.

5. Liu Zhou,Chen Yun,Shen Xiaorong.Combined application of energy saving technology and new energy in natatorium.[M].New Technology \& New Products of China.2015,(21).151-152. 